\title{
Theophylline and dexamethasone in combination reduce inflammation and prevent the decrease in HDAC2 expression seen in monocytes exposed to cigarette smoke extract
}

\author{
XUE-JIAO SUN ${ }^{1,2^{*}}$, ZHAN-HUA LI ${ }^{1,3^{*}}$, YANG ZHANG $^{1}$, XIAO-NING ZHONG ${ }^{1}$, \\ ZHI-YI HE ${ }^{1}$, JI-HONG ZHOU ${ }^{3}$, SI-NING CHEN ${ }^{3}$ and YUAN FENG ${ }^{3}$ \\ ${ }^{1}$ Department of Respiratory and Critical Care Medicine, The First Affiliated Hospital of Guangxi Medical University, \\ Nanning, Guangxi 530021; ${ }^{2}$ Department of Respiratory and Critical Care Medicine, Liuzhou People's Hospital, \\ Liuzhou, Guangxi 545006; ${ }^{3}$ Department of Respiratory Medicine, Ruikang Hospital Affiliated to \\ Guangxi Traditional Chinese Medicine University, Nanning, Guangxi 530021, P.R. China
}

Received December 23, 2018; Accepted September 20, 2019

DOI: $10.3892 /$ etm.2020.8584

\begin{abstract}
Lung and systemic inflammation are associated with impaired lung function and increased mortality in patients with chronic obstructive pulmonary disease (COPD). Theophylline and glucocorticoids have been shown to have an anti-inflammatory effect in some respiratory diseases. However, corticosteroid insensitivity is a major barrier to the anti-inflammatory management of COPD. This study aimed to explore whether a combined treatment of theophylline and dexamethasone (Dex) could decrease cigarette smoke extract (CSE)-induced inflammation via prevention of a reduction in histone deacetylase 2 (HDAC2) expression and through inhibition of the PI3K/Akt pathway, which may be related to corticosteroid sensitivity. The half-maximal inhibitory concentration $\left(\mathrm{IC}_{50}\right)$ of Dex $\left(\mathrm{IC}_{50}\right.$-Dex $)$ was used to as a marker of corticosteroid sensitivity. $\mathrm{IC}_{50}$-Dex was determined through observation of Dex inhibition of tumor necrosis factor- $\alpha$ (TNF- $\alpha$ )-induced interleukin (IL)- 8 release. Using reverse transcription quantitative PCR and western blotting, U937 cells treated with CSE were assessed for HDAC2 expression levels and phosphorylation levels of Akt. Theophylline and Dex pre-treatment was shown to significantly reduce the CSE-induced release of IL- 8 and TNF- $\alpha$. The combination of theophylline and Dex pretreatment also reversed corticosteroid insensitivity in CSE-induced U937 cells and inhibited
\end{abstract}

Correspondence to: Dr Xiao-Ning Zhong, Department of Respiratory and Critical Care Medicine, The First Affiliated Hospital of Guangxi Medical University, 6 Shuangyong Road, Nanning, Guangxi 530021, P.R. China

E-mail: xnzhong101@sina.com

*Contributed equally

Key words: chronic obstructive pulmonary disease, corticosteroid insensitivity, theophylline, dexamethasone, PI3K/Akt pathway the PI3K/AKT pathway to a greater extent than theophylline treatment alone. CSE-treated U937 cells showed a reduction in HDAC2 mRNA and protein expression compared with the control group. However, this effect was reduced after pre-incubation with the combined therapy or theophylline alone. In conclusion, pretreatment with theophylline and Dex decreased CSE-induced inflammation via inhibition of the $\mathrm{PI} 3 \mathrm{~K} / \mathrm{Akt}$ pathway and increase in HDAC2 protein expression.

\section{Introduction}

Chronic obstructive pulmonary disease (COPD) is characterized by persistent airflow limitation, which is usually progressive, and is associated with an enhanced chronic airway and pleural inflammatory response to noxious particles or gases $(1,2)$. COPD is on course to become a global health challenge in the near future. It is currently the fourth leading cause of death worldwide, but is soon expected to become the third (2).

The most important risk factor associated with COPD is cigarette smoking (1). Tobacco smoke and air pollutants are sources of oxidative stress, which is induced by an increased burden of inhaled oxidants and elevated levels of reactive oxygen species (ROS) released from inflammatory cells (3). Increases in levels of ROS, either directly or via the formation of lipid peroxidation products, contribute to an enhanced inflammatory response in COPD (3).

Corticosteroids have an anti-inflammatory effect in chronic inflammatory diseases such as asthma and diffuse panbronchiolitis (4). However, in COPD patients, the anti-inflammatory effects of glucocorticoids are limited (4). High-dose inhaled and oral glucocorticoids have a limited effect in reducing the production and release of inflammatory cells, cytokines and proteases, including tumor necrosis factor- $\alpha$ (TNF- $\alpha$ ), interleukin-8 (IL-8) and matrix metallopeptidase 9 (MMP-9) in COPD patients $(5,6)$. This suggests corticosteroid resistance in these patients. Dexamethasone (Dex) is a long-acting glucocorticoid that has routine application in clinical and experimental work (7-9). 
Histone acetyltransferases (HATs) and histone deacetylases (HDACs) are families of enzymes that regulate and affect inflammatory gene expression $(7,8)$. HATs can open chromatin structure by acetylation of the molecular modification protein to ensure the transcription factor and RNA polymerase bind to DNA for prompt gene transcription. However, HDACs ensure that the chromatin conformation remains closed, and thus block gene transcription $(10,11)$. Increasing evidence has shown that the acetylation-deacetylation imbalance may be the determining factor in corticosteroid resistance in COPD and, consequently, in the inability of conventional treatments to prevent inflammation-induced lung destruction $(12,13)$. HDAC2, a member of the class I HDAC family, has been shown to play a role in the regulation of cell inflammatory responses $(11,14)$. It has been reported that the impact of oxidative stress on chromatin regulation by a reduction in the activity of HDAC-2 leads to corticosteroid resistance in COPD $(3,15)$.

PI3Ks generate lipid second messengers that control an array of intracellular signaling pathways, which have important roles in inflammation (16). Oxidative stress not only reduces HDAC-2 activity and, thereby, glucocorticoid immunosuppression, but also activates the PI3K/Akt pathway $(17,18)$. PI3Ks are activated by cell-surface receptors, such as receptor tyrosine kinases and G-protein-coupled receptors, and serve to initiate intracellular signaling cascades through the generation of the lipid secondary messenger phosphatidylinositol-3,4,5-triphosphate (PIP3). PIP3 serves as a docking site for the pleckstrin homology domain of proteins such as the serine-threonine kinase Akt $(19,20)$. The class I PI3K isoforms, PI3K- $\delta$ and PI $3 \mathrm{~K}-\gamma$, are predominantly expressed in leukocytes and play a central role in inflammatory cell function (20). The oxidant-mediated induction of PI3K signaling is reportedly mediated primarily through PI3K- $\delta$, but not PI3K- $\gamma(20)$.

Theophylline is a long-established respiratory treatment that was originally used as a bronchodilator. At relatively high concentrations, theophylline directly inhibits phosphodiesterases and antagonizes adenosine receptors (21). In recent years, a combination of low-dose theophylline with glucocorticoids has been used to good anti-inflammatory effect, and shown to effectively reduce glucocorticoid resistance in patients with COPD $(9,22)$. Several studies have shown that low-dose theophylline reverses the reduction in HDAC2 expression, seen in macrophages, monocytes and epithelial cells challenged with oxidative stress, and in mice, rats, and human patients with COPD, to restore glucocorticoid sensitivity $(7,13,22,23)$.

In the current study, a combined theophylline and Dex treatment was used in an in vitro experiment to determine whether this drug combination has the potential to reduce CSE-induced inflammation through rescue of HDAC2 expression and inhibition of the PI3K/Akt pathway.

\section{Materials and methods}

Cell culture and treatments. U937 cells (human monocytic cell line; Type Culture Collection of the Chinese Academy of Sciences), as utilized previously (24), are routinely used to explore the mechanisms underlying inflammation in COPD. U937 cells were maintained in continuous cell culture at $37^{\circ} \mathrm{C}$ and $5 \% \mathrm{CO}_{2}$ in RPMI-1640 medium (GE Healthcare Life Sciences) supplemented with $10 \%$ fetal bovine serum
(GE Healthcare Life Sciences). U937 cells in the combined theophylline (Sigma-Aldrich; Merck KGaA) and Dex (Hubei Qianjiang Pharmaceutical Co., Ltd.) treatment group, or theophylline only treatment group, were incubated with theophylline and Dex $\left(10^{-6} \mathrm{M}\right)$ or theophylline $\left(10^{-3} \mathrm{M}\right)$ alone for $5 \mathrm{~h}$ prior to CSE exposure. U937 cells of the IC87114 group were treated with IC87114 $(1 \mu \mathrm{M})$ before CSE exposure. U937 cells in CSE treatment groups were stimulated with CSE for $12 \mathrm{~h}$.

Preparation of CSE. CSE was prepared using the methods developed by Mercado et al (25). Ten full-strength burning cigarettes without filters were continuously pumped with a syringe. The smoke was slowly dissolved into $10 \mathrm{ml}$ PBS and the $\mathrm{pH}$ value was adjusted to 7.4. This CSE solution was twice filtered through a $0.22 \mu \mathrm{m}$ filter membrane and used within $2 \mathrm{~h}$ of preparation. With PBS as the blank control, the optical density was measured at a wavelength of $320 \mathrm{~nm}$, and converted to provide a percentage CSE concentration.

MTT assay. U937 cells were plated in three 96-well plates at a density of $1.5 \times 10^{4} \mathrm{cell} / \mathrm{ml}$ and co-incubated with theophylline $\left(10^{-3}-10^{-6} \mathrm{~mol} / \mathrm{l}\right.$; Sigma-Aldrich; Merck KGaA) or CSE $(4,8,16$, or $32 \%)$. The compounds were added to a final volume of $100 \mu \mathrm{mol}$, and the cells were cultured for 24,48 , or $72 \mathrm{~h}$ at $37^{\circ} \mathrm{C}$. MTT solution $(10 \mu 1 \mathrm{of} 5 \mathrm{mg} / \mathrm{ml})$ was added to each well, and the cultures were incubated for an additional $4 \mathrm{~h}$. After removing the culture solution, $100 \mu \mathrm{l}$ DMSO solution was added and the plates were shaken at low speed for $10 \mathrm{~min}$. The absorbance at $570 \mathrm{~nm}$ in each well was determined using a 96-well plate reader. The proliferation of treated cells was compared to that of control cells.

TNF- $\alpha$ assay. TNF- $\alpha$ concentrations in the supernatant were evaluated by ELISA (96-well plates; R\&D Systems Inc.; cat. no. DY210) in accordance with the manufacturer's instructions.

$I L-8$ assay and $I C_{50}$-Dex calculation. U937 cells in the CSE group were treated with CSE (8\%) for $12 \mathrm{~h}$, and then incubated with Dex for 45 min before stimulation with TNF- $\alpha$ $\left(10 \mathrm{ng} / \mathrm{ml}\right.$; PreproTech) at $37^{\circ} \mathrm{C}$ overnight. U937 cells in drug treatment groups were incubated with theophylline $\left(10^{-3} \mathrm{M}\right)$ and Dex $\left(10^{-6} \mathrm{M}\right)$, theophylline alone, or IC87114 $(1 \mu \mathrm{M})$, respectively, for $5 \mathrm{~h}$ prior to their treatment with CSE for $12 \mathrm{~h}$ and subsequent treatment with Dex $\left(10^{-11}, 10^{-10}, 10^{-9}, 10^{-8}, 10^{-7}\right.$ and $\left.10^{-6} \mathrm{M}\right) 45 \mathrm{~min}$ before stimulation with TNF- $\alpha(10 \mathrm{ng} / \mathrm{ml})$. IL-8 concentrations in the supernatant were evaluated by ELISA (96-well plates; R\&D Systems Inc.) according to the manufacturer's instructions. In the current study, the $\mathrm{IC}_{50}$ of dexamethasone $\left(\mathrm{IC}_{50}\right.$-Dex) was used as a marker for corticosteroid sensitivity, and was determined based on the inhibition of IL-8 release at different Dex concentrations $\left(10^{-11}, 10^{-10}, 10^{-9}\right.$, $10^{-8}, 10^{-7}$ and $\left.10^{-6} \mathrm{M}\right)(24)$.

Reverse transcription-quantitative polymerase chain reaction (RT-qPCR, SYBR Green Master Mix, Life Technologies). Total RNA was extracted from treated cells using TRIzol ${ }^{\circledR}$ (Invitrogen, Thermo Fisher Scientific, Inc.). The quality and quantity of total RNA was analyzed using a spectrophotometer. 
The RNA samples were reverse transcribed into cDNA using a reverse transcription kit (Transcriptor first strand cdna synthesis kit; Sigma-Aldrich; Merck KGaA) using the following temperature protocol: $95^{\circ} \mathrm{C}$ for $5 \mathrm{sec}$ followed by $60^{\circ} \mathrm{C}$ for $30 \mathrm{sec}$. To determine the mRNA expression levels, the following primers were used: HDAC2 forward, 5'-CAA TCTAACTGTCAAAGGTCATGC-3' and reverse, 5'-TGA AGTCTGGTCCAAAATACTCAA-3'; and $\beta$-actin forward, 5'-ACACTGTGCCCATCTACG-3' and reverse, 5'-TGTCAC GCACGATTTCC-3'. The $2^{-\Delta \Delta \mathrm{Cq}}$ method (26) was used for relative quantification. Amplification was performed using an ABI 9700 real-time PCR instrument (Thermo Fisher Scientific, Inc.). The thermocycling conditions were as follows: Pre-denaturation at $95^{\circ} \mathrm{C}$ for $30 \mathrm{sec}$ and denaturation at $95^{\circ} \mathrm{C}$ for $5 \mathrm{sec}$, followed by 40 cycles of annealing at $60^{\circ} \mathrm{C}$ for $5 \mathrm{sec}$, elongation $60^{\circ} \mathrm{C}$ for $30 \mathrm{sec}$ and extension at $60^{\circ} \mathrm{C}$ for $30 \mathrm{sec}$. Suitable cycle numbers were determined in accordance with the standard plasmid amplification curve in RT-qPCR using Rotor-Gene Real-time Analysis Software version 6.1 (Qiagen, Inc.). The mRNA values of HDAC2 transcripts were normalized to that of $\beta$-actin (23).

Western blotting. Proteins were extracted from the treated cells using RIPA buffer (Pierce; Thermo Fisher Scientific, Inc.). Protein quantification was undertaken using bicinchoninic acid (BCA; Pierce, Thermo Fisher Scientific, Inc.) according to the manufacturer's instructions. For HDAC2, PI3K, phosphorylated (p)-Akt and Akt, $20 \mu \mathrm{g}$ of each sample was analyzed on an SDS-PAGE (10\% gel), then transferred onto nitrocellulose membranes, which were then blocked with $5 \%$ bovine serum albumin (Pierce; Thermo Fisher Scientific, Inc.) dissolved in Tris-buffered saline with $0.1 \%$ Tween-20 at $4^{\circ} \mathrm{C}$ overnight. The membranes were incubated for $12 \mathrm{~h}$ at $4^{\circ} \mathrm{C}$ with the following rabbit anti-human primary polyclonal antibodies (each, 1:2,000; R\&D Systems, Inc.): catalogue numbers: HDAC2 (cat. no. MAB7679), PI3K (cat. no. MAB2687), Akt (cat.no. MAB2055) and p-Akt (cat. no. AF887). Thereafter, the membranes were incubated with secondary antibody (horseradish peroxidase-conjugated goat anti-rabbit IgG, (1:10,000; R\&D Systems, Inc.; cat. no. AF789), and the blots were visualized with enhanced chemiluminescence (ECL luminescent substrate; Pierce; Thermo Fisher Scientific, Inc.). Mouse anti-human GAPDH antibody (1:10,000; R\&D Systems; cat. nos. AF5781) was used as a protein loading control. Desnitometry was performed using AlphaView software (NatureGene Corporation).

Statistical analysis. All data were analyzed using SPSS software (version 17.0; SPSS, Inc.). All quantitative data are presented as the mean \pm SD of three independent repeats. Multiple comparisons were performed using one-way ANOVA followed by a Tukey's post hoc test. In data with a non-normal distribution, variance was determined by Kruskal-Wallis analysis, followed by Dunn's multiple comparison tests. $\mathrm{P}<0.05$ was considered to indicate a statistically significant difference.

\section{Results}

Effects of CSE or theophylline on the growth of U937 cells. Cell-proliferation assays were conducted, using a range of concentrations of CSE and theophylline, in order to determine whether exposure to CSE or theophylline was cytotoxic. Compared with the control group, the proliferation of CSE-stimulated U937 cells (4 and 8\% CSE) did not change significantly over a period of 24,48 and $72 \mathrm{~h}$ [CSE (4\%), $0.689 \pm 0.055,1.083 \pm 0.042$ and $1.172 \pm 0.06$; CSE $(8 \%)$, $0.593 \pm 0.063,0.928 \pm 0.061$ and $0.996 \pm 0.046$; control group, $0.716 \pm 0.051,0.954 \pm 0.056$ and $1.142 \pm 0.038]$. However, concentrations of $16 \%$ and $32 \%$ CSE significantly slowed down cell growth [CSE (16\%), 0.484 $\pm 0.057,0.518 \pm 0.044$ and $0.528 \pm 0.075$; CSE (32\%), 0.266 $\pm 0.032,0.209 \pm 0.078$ and $0.199 \pm 0.081$; control group, $0.716 \pm 0.051,0.954 \pm 0.056$ and $1.142 \pm 0.038)$. There were no marked changes in cells treated with theophylline $\left(10^{-3}-10^{-6} \mathrm{~mol} / \mathrm{l}\right)$, when compared with the control group, over a period of 24,48 and $72 \mathrm{~h}$ [theophylline $\left(10^{-6} \mathrm{~mol} / \mathrm{l}\right)$ 0.702lline2, $0.92621 \mathrm{line}$ and 0.9942 lline2; theophylline $\left(10^{-5} \mathrm{~mol} / \mathrm{l}\right), 0.668 \pm 0.036,1.019 \pm 0.047$ and $1.032 \pm 0.056$; theophylline $\left(10^{-4} \mathrm{~mol} / \mathrm{l}\right), 0.654 \pm 0.043,0.947 \pm 0.068$ and $1.066 \pm 0.072$; theophylline $\left(10^{-3} \mathrm{~mol} / \mathrm{l}\right), 0.672 \pm 0.066,0.98 \pm 0.048$ and 1.083 \pm 0.035 ; control group, $0.716 \pm 0.051,0.954 \pm 0.056$ and $1.142 \pm 0.038)$. Table I.

Theophylline-Dex pretreatment inhibits $T N F-\alpha$ release in CSE-exposed U937 cells. U937 cells were incubated with theophylline and Dex, theophylline alone, or IC87114 $(1 \mu \mathrm{M})$ alone, respectively, for $5 \mathrm{~h}$ prior to 12-h incubation with CSE. CSE-stimulation of U937 cells markedly increased the level of TNF $\alpha$ released into the supernatant when compared with the control group. Pretreatment with theophylline significantly reduced the level of TNF- $\alpha$ released by U937 cells exposed to CSE when compared with the CSE group. However, a combination of theophylline and Dex pretreatment was significantly more effective in reducing $\mathrm{TNF} \alpha$ release than theophylline alone. As a positive control, pretreatment with IC87114 was used and shown to inhibit the increased release of TNF $\alpha$ in response to CSE (Fig. 1).

Theophylline-Dex pretreatment reduces CSE-induced corticosteroid insensitivity. Treatment with CSE (8\%) significantly increased $\mathrm{IC}_{50}$-Dex $\left(1.72 \pm 0.91 \times 10^{-5} \mathrm{~mol} / 1\right.$ vs. control, $\left.2.23 \pm 0.78 \times 10^{-8} \mathrm{~mol} / \mathrm{l} ; \mathrm{P}<0.05\right)$, which was reduced in cells pretreated with theophylline $\left(1.90 \pm 0.52 \times 10^{-7} \mathrm{~mol} / \mathrm{l}\right)$. A combination of theophylline and Dex was more effective than theophylline alone $\left(8.71 \pm 0.64 \times 10^{-8} \mathrm{~mol} / \mathrm{l}\right)$. A positive control, CSE-treated U937 cells (7\%) pretreated with IC87114, could inhibit the increase of $\mathrm{IC}_{50}\left(2.31 \pm 0.94 \times 10^{-7} \mathrm{~mol} / \mathrm{l}\right)$ compared with the CSE group. The results showed that U937 cells treated with CSE were less sensitive to Dex compared with the control group, but that sensitivity was increased in cells that had been pretreated with a combination treatment or theophylline alone. Furthermore, combination therapy showed an additive effect (Fig. 2).

Theophylline-Dex pretreatment reduces the decrease in HDAC2 mRNA expression seen in CSE-treated cells. U937 cells treated with CSE expressed significantly reduced levels of HDAC2 mRNA when compared with control cells, an effect which was reduced in cells pre-incubated with a combination of theophylline and Dex or theophylline alone. A combination treatment was significantly more effective in preventing 
Table I. Absorbance values of U937 cells exposed to different concentrations of CSE and theophylline (mean \pm SD; $n=6$ ).

\begin{tabular}{lccc}
\hline Groups & $24 \mathrm{~h}$ & $48 \mathrm{~h}$ & $72 \mathrm{~h}$ \\
\hline Comtrol group & $0.716 \pm 0.051$ & $0.954 \pm 0.056$ & $1.142 \pm 0.038$ \\
CSE (4\%) & $0.689 \pm 0.055$ & $1.083 \pm 0.042$ & $1.172 \pm 0.06$ \\
CSE (8\%) & $0.593 \pm 0.063$ & $0.928 \pm 0.061$ & $0.996 \pm 0.046$ \\
CSE $(16 \%)$ & $0.484 \pm 0.057^{\mathrm{a}}$ & $0.518 \pm 0.044^{\mathrm{a}}$ & $0.528 \pm 0.075^{\mathrm{a}}$ \\
CSE $(32 \%)$ & $0.266 \pm 0.032^{\mathrm{a}}$ & $0.209 \pm 0.078^{\mathrm{a}}$ & $0.199 \pm 0.081^{\mathrm{a}}$ \\
Theophylline $\left(10^{-6} \mathrm{~mol} / \mathrm{l}\right)$ & $0.702 \pm 0.045$ & $0.926 \pm 0.059$ & $0.994 \pm 0.0 .35$ \\
Theophylline $\left(10^{-5} \mathrm{~mol} / \mathrm{l}\right)$ & $0.668 \pm 0.036$ & $1.019 \pm 0.047$ & $1.032 \pm 0.056$ \\
Theophylline $\left(10^{-4} \mathrm{~mol} / \mathrm{l}\right)$ & $0.654 \pm 0.043$ & $0.947 \pm 0.068$ & $1.066 \pm 0.072$ \\
Theophylline $\left(10^{-3} \mathrm{~mol} / \mathrm{l}\right)$ & $0.672 \pm 0.066$ & $0.98 \pm 0.048$ & $1.083 \pm 0.035$ \\
\hline
\end{tabular}

${ }^{\mathrm{a}} \mathrm{P}<0.001$ vs. control group. CSE, cigarette smoke extract.

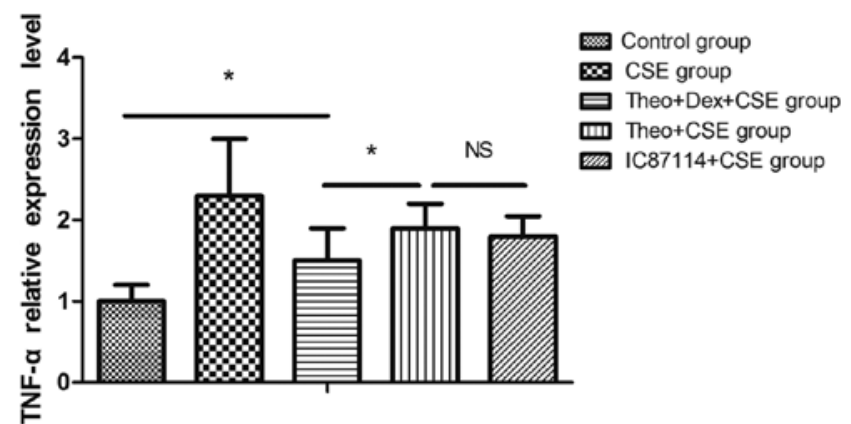

Figure 1. Relative levels of TNF- $\alpha$ release in the medium of CSE-treated U937 cells. "P<0.05. CSE, cigarette smoke extract; Dex, dexamethasone; IC87114, phosphoinositide 3 kinase- $\delta$ inhibitor; NS, not significant; TNF- $\alpha$, tumor necrosis factor $\alpha$; U937, human macrophage cell line.

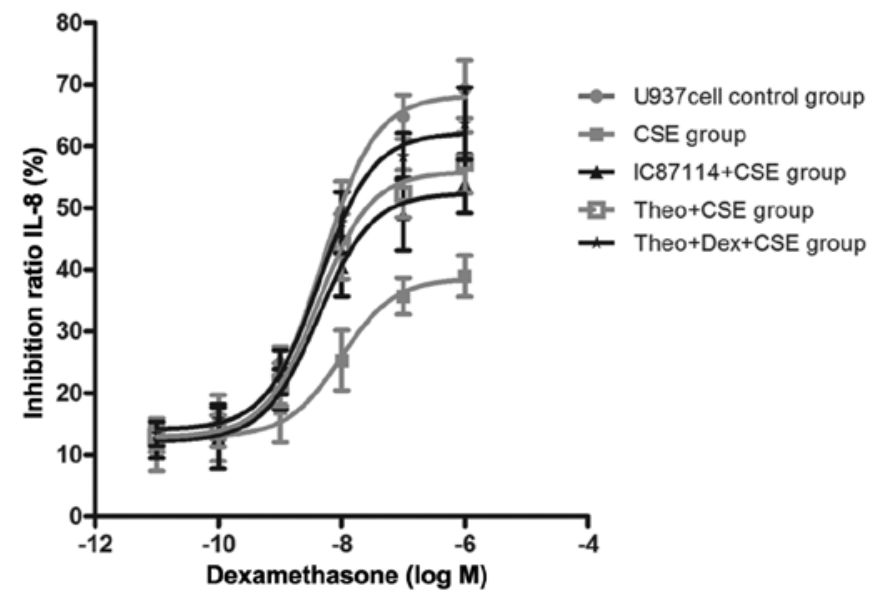

Figure 2. Corticosteroid sensitivity in CSE-induced U937 cells. CSE, cigarette smoke extract; Dex, dexamethasone; IC87114, phosphoinositide 3 kinase- $\delta$ inhibitor; IL, interleukin; TNF- $\alpha$, tumor necrosis factor $\alpha$; U937, human macrophage cell line.

HDAC2 reduction than theophylline treatment alone. As a positive control, pretreatment with IC87114 was also shown to significantly decrease the level of reduction of HDAC 2 mRNA expression when compared with the CSE group. $(\mathrm{P}<0.05)$ (Fig. 3).

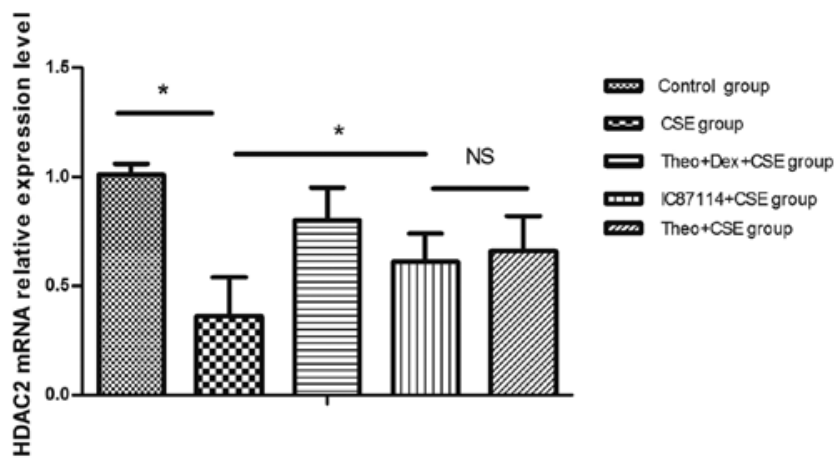

Figure 3. Pretreatment of U937 cells with theophylline and Dex restores HDAC2 mRNA expression in cells treated with CSE. ${ }^{*} \mathrm{P}<0.05$. CSE, cigarette smoke extract; Dex, dexamethasone; HDAC2, histone deacetylase 2; IC87114, phosphoinositide 3 kinase- $\delta$ inhibitor; U937, human macrophage cell line; NS, not significant.

Theophylline-Dex pretreatment reduces the decrease in HDAC2 protein expression seen in CSE-treated cells. U937 cells treated with CSE showed a reduction in HDAC2 protein expression, which was reversed in cells pretreated with a combination treatment of theophylline and Dex or theophylline alone; however, the combination treatment was especially effective. As a positive control, pretreatment with IC87114 was shown to decrease the reduction in HDAC2 protein expression in U937 cells exposed to CSE (Fig. 4).

Theophylline-Dex combination decreases Akt phosphorylation and does not affect Akt and PI3K expression levels. CSE increased the phosphorylation of Akt protein in U937 cells, and this was reversed by theophylline. Furthermore, a combination of theophylline and Dex significantly decreased the phosphorylation level of Akt protein in U937 cells exposed to CSE compared with theophylline alone (Fig. 5). As the positive control, IC87114 decreased Akt phosphorylation level in CSE-stimulated cells compared with the CSE group. CSE, theophylline, IC87114, or combination of theophylline and DEX did not affect PI3K or total Akt protein expression (Fig. 6). 

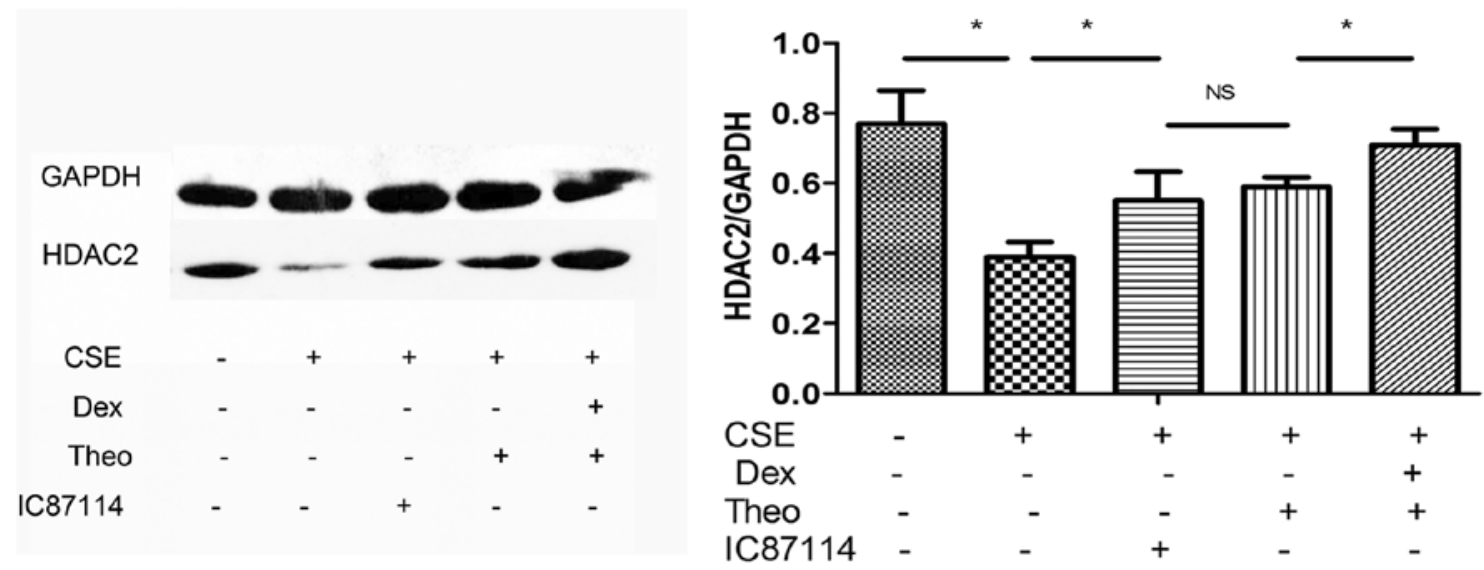

Figure 4. Pretreatment of U937 cells with theophylline and Dex restores HDAC2 protein expression in cells treated with CSE. "P<0.05. CSE, cigarette smoke extract; Dex, dexamethasone; HDAC2, histone deacetylase 2; IC87114, phosphoinositide 3 kinase- $\delta$ inhibitor; NS, not significant; U937, human macrophage cell line.
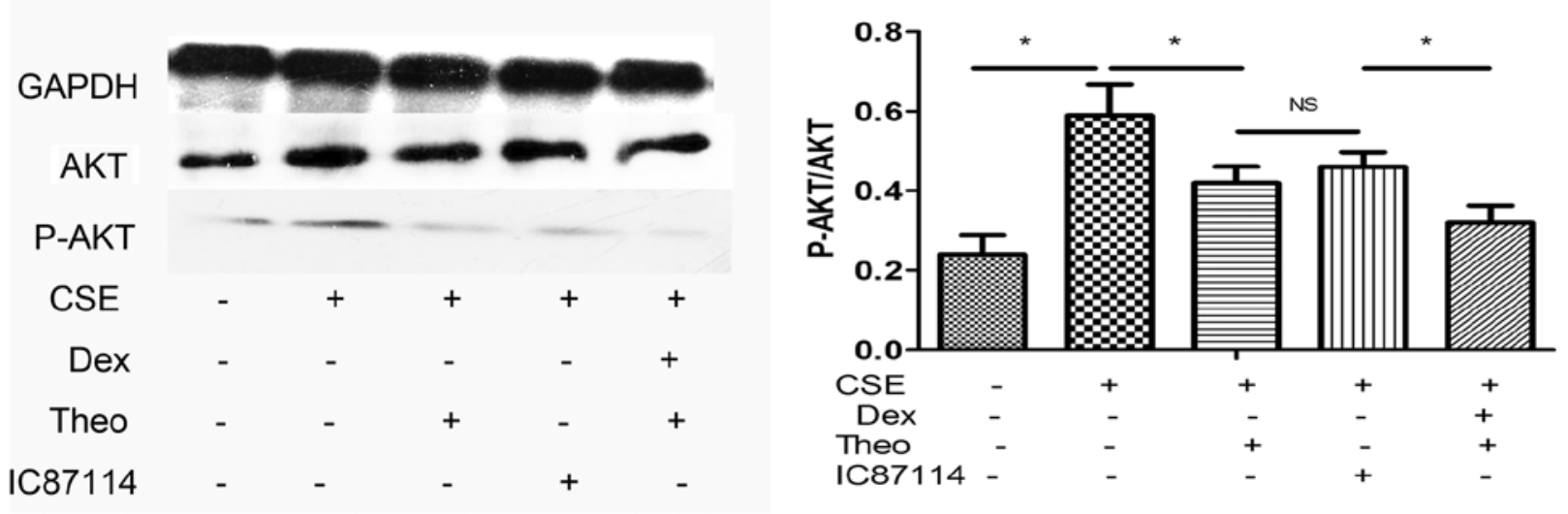

Figure 5. p-Akt protein level after CSE treatment. "P<0.05. CSE, cigarette smoke extract; Dex, dexamethasone; IC 87114 , phosphoinositide 3 kinase- $\delta$ inhibitor; p, phosphorylated; U937, human macrophage cell line; NS, not significant.
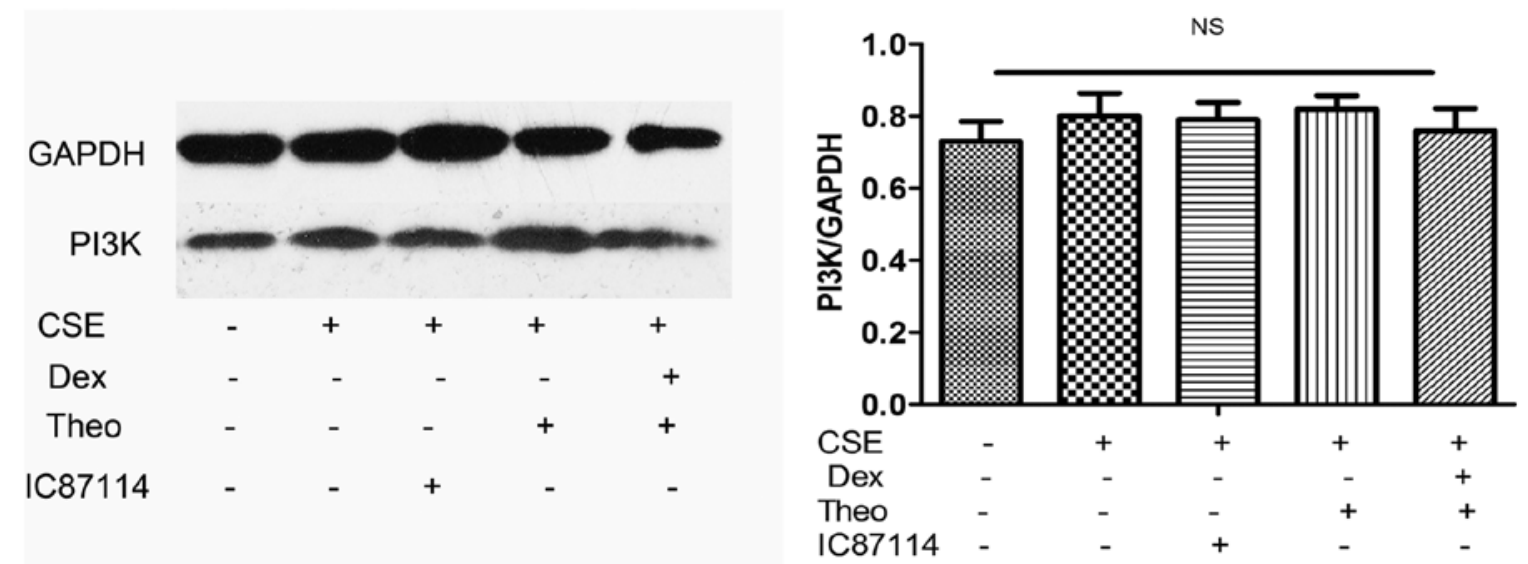

Figure 6. PI3K protein expression after CSE treatment. CSE, cigarette smoke extract; Dex, dexamethasone; NS, not significant; PI3K, phosphoinositide 3 kinase; U937, human macrophage cell line.

\section{Discussion}

Corticosteroids are the most effective anti-inflammatory treatment for a number of inflammatory and immune diseases, including asthma, rheumatoid arthritis, inflammatory bowel disease, autoimmune diseases and COPD (14). However, some patients with severe COPD have a poor response to high-dose corticosteroid therapy (14). Corticosteroids have 
been shown to have almost no effect on alveolar macrophages from patients with $\mathrm{COPD}(8,27)$. The $\mathrm{IC}_{50}$ represents the concentration of a substance that is required to induce half of the maximum inhibition of a biological factor or function and is commonly used as a measure of inhibition effectiveness. In the present study, U937 cells were stimulated by $\mathrm{CSE}$, and $\mathrm{IC}_{50}$-Dex was used as a marker to examine corticosteroid sensitivity, as described previously (24). The results showed that CSE-stimulated cells were less corticosteroid sensitive than control cells, suggesting that CSE could cause corticosteroid resistance in U937 cells in vitro.

A number of studies have shown that low-dose theophylline can reverse corticosteroid resistance in patients with COPD and in smoke-induced rat models (12,21-23). A study by To et al (9) showed that theophylline inhibited the activity of PI3K- $\delta$ that had been precipitated from $\mathrm{H}_{2} \mathrm{O}_{2}$-treated cells. However, it is unknown whether a combination of theophylline and Dex would be more effective in reversing corticosteroid resistance and decreasing CSE-induced inflammation. The major aim of the current study was to explore the effect of a combination treatment of theophylline and Dex on the inflammation in CSE-induced U937 cells and to evaluate the underlying mechanism.

The results showed that the expression levels of PI3K and total Akt protein were not significantly different among the CSE, IC87114, combination treatment, theophylline and control groups. A previous report had indicated that PI3K expression in peripheral lung macrophages from smokers with normal lung function did not increase when compared with macrophages from nonsmokers with normal lung function (19). Those authors suggested that CSE could not affect PI3K or Akt expression in cells. However, in the current study, the phosphorylation level of Akt of CSE-stimulated cells was higher than that of cells in the control group. The p-Akt protein level of cells pretreated with theophylline and Dex or theophylline alone was lower than that of cells stimulated by only CSE. Combination treatment had a stronger effect. Moreover, IC87114, the positive control, could decrease p-Akt levels following CSE stimulation. These results suggested that CSE stimulation could activate the PI3K/Akt pathway and reduce corticosteroid sensitivity. The combination of theophylline and Dex significantly restored corticosteroid sensitivity and decreased CSE-induced inflammation through inhibition of PI3K/Akt pathway activation. In the current study, p-PI3K protein was not assessed, as p-Akt was sufficient to represent the activity of the PI3K/Akt pathway. This was congruent with previous studies $(8,9,24)$.

Previous studies have shown that HDAC2 expression was lowest in COPD patients who were non-smokers for more than 1 year when compared with healthy people, healthy smokers and smokers with COPD. Moreover, the HDAC2 expression level was gradually reduced $(23,24,28)$. This suggested that oxidative stress induced by tobacco smoke exposure reduced HDAC2 expression, which is an important cause of corticosteroid resistance (23). It was reported that low-dose theophylline could increase HDAC2 activity and restore glucocorticoid receptor sensitivity of pulmonary macrophages (21). The results of the present study showed that HDAC2 expression in CSE-stimulated U937 cells was lower than that of control cells. Furthermore, HDAC2 expression in cells pretreated with theophylline and Dex was higher than that in cells pretreated with theophylline alone. Therefore, this combination treatment was more effective in restoring the HDAC2 expression of CSE-stimulated U937 cells in vitro.

To the best of our knowledge, there is no known evidence that PI3K/Akt can directly affect HDAC2 expression. However, there may be some signaling molecules that provide a link between the PI3K/Akt pathway and HDAC2 and indirectly modulate the influence of PI3K/Akt on HDAC2. Ngkelo (29) showed that the activation of glycogen synthase kinase $3 \beta$ (GSK $3 \beta$ ) could reverse corticosteroid resistance under oxidative stress by increasing HDAC2 expression. Glycyrrhizic acid inhibited inflammatory factors by mediation of the PI3K/Akt/GSK3 $\beta$ pathway (30). Thus, GSK3 $\beta$ may be the connection between PI3K/Akt and HDAC2. However, whether other signaling molecules play an important role in the relationship between PI3K/AKT and HDAC2 requires further investigation (31).

In conclusion, a CSE-stimulated cell model was developed to study the influence of theophylline and Dex on the inflammatory effect and to explore the underlying mechanisms. Theophylline and Dex in combination or theophylline alone were able to reverse corticosteroid insensitivity and decrease inflammation via inhibition of the PI3K/Akt pathway and rescue of HDAC2 expression. A combination of theophylline and Dex treatment was more effective than theophylline treatment alone. This experiment has potential clinical significance, as it suggested that the combination of theophylline and Dex may be more beneficial in the treatment of COPD and other inflammatory diseases associated with smoke exposure than existing treatments.

\section{Acknowledgements}

The authors wish to thank Dr Zhiyi He (Department of Respiratory and Critical Care Medicine, The First Affiliated Hospital of Guangxi Medical University) for assistance with the design of the present study.

\section{Funding}

This study was financially supported by the National Nature Science Foundation of China (grant no. 81160009), Science and Technology Department of Guangxi Province (grant no. 1598012-26) and the Liuzhou Science Research and Technology Development Project (grant no. 2018BJ10507).

\section{Availability of data and materials}

All data generated or analyzed during this study are included in this article.

\section{Authors' contributions}

XNZ designed the current study. XJS, ZHL, YZ, ZYH performed the experiments. JHZ, SNC, YF analyzed the data. XJS and ZHL wrote the manuscript. XJS and ZHL revised the manuscript. All authors read and approved the final manuscript. 


\section{Competing interests}

The authors declare that they have no competing interests.

\section{References}

1. Osthoff M, Jenkins C and Leuppi J: Chronic obstructive pulmonary disease-a treatable disease. Swiss Med Wkly 143: w13777, 2013.

2. Vestbo J, Hurd SS, Agusti AG, Jones PW, Vogelmeier C, Anzueto A, Barns PJ, Fabbri LM, Martinez FJ, Nishimura M, et al: Global strategy for the diagnosis, management, and prevention of chronic obstructive pulmonary disease: GOLD executive summary. Am J Respir Crit Care Med 187: $347-365,2013$

3. Kirkham P and Rahman I: Oxidative stress in asthma and COPD: Antioxidants as a therapeutic strategy. Pharmacol Ther 111: 476-494, 2006.

4. Barnes P: Inhaled corticosteroids are beneficial in chronic obstructive pulmonary disease. Am J Respir Crit Care Med 161: 341-342; discussion 344, 2000.

5. Culpitt SV, Maziak W, Loukidis S, Nightingale JA, Matthews JL and Barnes PJ: Effect of high dose inhaled steroid on cells, cytokines and proteases in induced sputum in chronic obstructive pulmonary disease. Am J Respir Crit Care Med 160: 1635-1639, 1999.

6. Hattotuwa KL, Gizycki MJ, Ansari TW, Jeffery PK and Barnes NC: The effects of inhaled fluticasone on airway inflammation in chronic obstructive pulmonary disease. Am J Respir Crit Care Med 165: 1592-1596, 2002.

7. Ford PA, Durham AL, Russell RE, Gordon F, Adcock IM and Barnes PJ: Treatment effects of low-dose theophylline combined with an inhaled corticosteroid in COPD. Chest 137: 1338-1644, 2010.

8. Kobayashi Y, Wada H, Rossios C, Takagi D, Charron C, Barnes PJ and Ito $\mathrm{K}$ : A novel macrolide/fluoroketolide, solithromycin (CEM-101), reverses corticosteroid insensitivity via phosphoinositide 3-kinase pathway inhibition. Br J Pharmacol 169: 1024-1034, 2013

9. To Y, Ito K, Kizawa Y, Failla M, Ito M, Kusama T, Elliott WM, Hogg JC, Adcock IM and Barnes PJ: Targeting phosphoinositide-3-kinase-delta with theophylline reverses corticosteroid insensitivity in chronic obstructive pulmonary disease. Am J Respir Crit Care Med 182: 897-904, 2010.

10. Barnes PJ, Adcock IM and Ito K: Histone acetylation and deacetylation: Importance in inflammatory lung diseases. Eur Respir J 25: 552-563, 2005.

11. Rahman I and Adcock IM: Oxidative stress and redox regulation of lung inflammation in COPD. Eur Respir J 28: 219-242, 2006.

12. Sun X, Li Q, Gong Y, Ren L, Wan H and Deng W: Low-dose theophylline restores corticosteroid responsiveness in rats with smoke-induced airway inflammation. Can J Physiol Pharmacol 90: 895-902,2012.

13. De Ruijter AJ, van Gennip AH, Caron HN, Kemp S and van Kuilenburg AB: Histone deacetylases (HDACs) Characterization of the classical HDAC family. Biochem J 370 737-749, 2003

14. Barnes PJ and Adcock IM: Glucocorticoid resistance in inflammatory diseases. Lancet 373: 1905-1917, 2000.

15. Ito K, Caramori $\mathrm{G}$ and Adcock IM: Therapeutic potential of phosphatidylinositol 3-kinase inhibitors in inflammatory respiratory disease. J Pharmacol Exp Ther 321: 1-8, 2007.
16. Ito K, Lim S, Caramori G, Chung KF, Barns PJ and Adcock IM Cigarette smoking reduces histone deacetylase 2 expression, enhances cytokine expression, and inhibits glucocorticoid actions in alveolar macrophages. FASEB J 15: 1110-1112, 2001.

17. Barned PJ: Cellular and molecular mechanisms of asthma and COPD. Clin Sci (Lond) 131: 1541-1558, 2017.

18. Kok K, Geering B and Vanhaesebroeck B: Regulation of phosphoinositide 3-kinase expression in health and disease. Trends Biochem Sci 34: 115-127, 2009.

19. Marwick JA, Caramori G, Casolari P, Mazzoni F, Kirkham PA, Adcock IM, Chung KF and Papi A: A role for phosphoinositol 3-kinase delta in the impairment of glucocorticoid responsiveness in patients with chronic obstructive pulmonary disease. J Allergy Clin Immunol 125: 1146-1153, 2010.

20. Ichiyama T, Hasegawa S, Matsubara T, Hayashi $T$ and Furukawa S: Theophylline inhibits NF-kappa B activation and I kappa B alpha degradation in human pulmonary epithelial cells. Naunyn Schmiedebergs Arch Pharmacol 364: 558-561, 2001.

21. Cosio BG, Tsaprouni L, Ito K, Jazrawi E, Adcock IM and Barns PJ: Theophylline restores histone deacetylase activity and steroid responses in COPD macrophages. J Exp Med 200: 689-695, 2004.

22. Cosio BG, Iglesias A, Rios A, Noguera A, Sala E, Ito K, Barns PJ and Agusti A: Low-dose theophylline enhances the anti-inflammatory effects of steroids during exacerbations of COPD. Thorax 64: 424-429, 2009.

23. Li M,Zhong X, He Z, Wen M, Li J, Peng X, Liu G, Deng J,Zhang J and Bai J: Effect of erythromycin on cigarette-induced histone deacetylase protein expression and nuclear factor $-\kappa \mathrm{B}$ activity in human macrophages in vitro. Int Immunopharmacol 12: 643-650, 2012

24. Sun XJ, Li ZH, Zhang Y, Zhou G, Zhang JQ, Deng JM, Bai J, Liu GN, Li MH, MacNee W, et al: Combination of erythromycin and dexamethasone improves corticosteroid sensitivity induced by cigarette smoke extract through inhibition of PI3K- $\delta / \mathrm{Akt}$ pathway and increased GR expression. Am J Physiol Lung Cell Mol Physiol 309: L139-L146, 2015.

25. Mercado N, To Y, Ito K and Barnes PJ: Nortriptyline reverses corticosteroid insensitivity by inhibition of phosphoinositide-3-kinase- $\delta$. J Pharmacol Exp Ther 337: 465-470, 2011.

26. Livak KJ and Schmittgen TD: Analysis of relative gene expression data using real-time quantitative PCR and the 2(-Delta Delta C (T)) method. Methods 25: 402-408, 2001.

27. Culpitt SV, Rogers DF, Shah P, De Matos C, Russell RE, Donnelly LE and Barnes PJ: Impaired inhibition by dexamethasone of cytokine release by alveolar macrophages from patients with chronic obstructive pulmonary disease. Am J Respir Crit Care Med 167: 24-31, 2003.

28. Szulakowski P, Crowther AJ, Jimenez LA, Donaldson K, Mayer R, Leonard TB, Macnee W and Drost EM: The effect of smoking on the transcriptional regulation of lung inflammation in patients with chronic obstructive pulmonary disease. Am J Respir Crit Care Med 174: 41-50, 2006.

29. Ngkelo A: The role of GSK3 $\beta$ in regulating corticosteroid function under conditions of oxidative stress in chronic obstructive pulmonary disease. Imperial College 2012.

30. Ortiz JL, Milara J, Lluch J, De Diego A, Sanz C and Cortijo J: Phosphodiesterase-4 inhibition improves corticosteroid insensitivity in pulmonary endothelial cells under oxidative stress. Allergy 68: 64-73, 2013.

31. Hennessy BT, Smith DL, Ram PT, Lu Y and Mills GB: Exploiting the PI3K/AKT pathway for cancer drug discovery. Nat Rev Drug Discov 4: 988-1004, 2005. 